\title{
Collecting Globally, Connecting Locally: 21st Century Libraries
}

\author{
Susan Edwards, Chan Li, Celia Emmelhainz, Adam Clemons, Liladhar Pendse, and \\ Natalia Estrada \\ University of California, Berkeley, USA
}

\section{Introduction}

Just a few decades ago, bibliographers at research libraries strove to build the largest, most comprehensive collections-with material from as many countries and in as many languages- as the budget would allow. Having a high percentage of unique items was desirable, and usage was not a core indicator of value. In fact, many ascribed to the philosophy that if one patron used a book one time in one hundred years, then the acquisition of that book helped fulfil the mission of the research library.

But the expectation for today's collection development librarians has changed. Given the reality of fixed (or decreasing) budgets, rising serials costs, an explosion in scholarly publishing, a diverse array of new formats, and the rapid growth of new academic programs and fields of study, collection development librarians are expected to build collections more closely aligned with the institution's teaching and research needs.

Understanding how well the collections we build meet the needs of our users is challenging for all librarians, but it is particularly challenging in area studies. The number of publications-and the range of languagesthat might be of use to researchers is vast, but usage is inherently low. An analysis done at Berkeley demonstrated this discrepancy, finding that the average cost per circulation for international and area studies materials compared to all other subject areas was 6:1. It is worth noting that this cost per use ratio underreports the total cost per use discrepancy because it does not include the cost of cataloging. Cataloging costs, especially for the less commonly taught languages (any other language than English, French, German, and Spanish), is significantly higher than for English.

But less use may not mean less value, so what evidence besides circulation and e-usage data can selectors gather to make informed decisions about what is needed to support the faculty's global research interests? And further, how might we determine the appropriate allocation of funds to support global studies, and the appropriate balance of English and non-English language sources within area studies?

We decided to focus on faculty behaviors in order to get a deeper understanding of the impact of nonEnglish language resources on their scholarship. Citation analysis is a uniquely powerful method because it analyzes all resources that the author used to support his/her thesis. Scholarly citations and bibliographies include resources not owned by the library (or by any library) which usage data-even interlibrary loan data-cannot provide. Analyzing the citations also addresses the concern that many publishers of foreign language materials do not currently provide online usage data.

But behavior alone is not enough; we also wanted to understand faculty beliefs about the value of nonEnglish language material for their teaching and research. To get a better understanding of their attitudes, we decided to use a survey, followed up by interviews with faculty who agreed to talk with us so we could get a more in-depth understanding of their needs.

\section{Literature Review}

Several studies have explored the use and impact of foreign language material on scholarship, primarily through citation analysis. Kellsey and Knievel's 2005 longitudinal analysis of journals in several humanities disciplines, including history, investigated whether the percentage of foreign language citations decreased over time (1962-2002). They found that the number of foreign citations did not drop but the percentage didas the number of English language sources rose, quite significantly in some disciplines. In their article, they 
describe $6.7 \%$ of citations in German as "unusually high" and 11.1\% in Italian to be "extraordinary." Interestingly, these percentages have become a benchmark in subsequent studies.

Schadl and Todeschini's 2015 study analyzed the citations of 179 dissertations on Latin America completed at the University of New Mexico from 2000-2009, and found that, overall, 12\% of the articles cited and 16\% of the books were in Spanish. The percentage varied by department, and in the history of art (which grants few dissertations, so is not well reflected by the average), it was as high as $54 \%$. They concluded that Spanish language material was essential to research in Latin American studies and justified the expenditure, but that Portuguese did not.

Edwards et al., 2017, analyzed the use of non-English language sources in 5,668 dissertations from 98 departments at UC Berkeley, 2008-2015. Overall, $4 \%$ of the total citations were to non-English language sources, but this varied widely by discipline, ranging from $57 \%$ to $7 \%$ in the twenty departments with the highest use. Not surprisingly, these were the departments that emphasize languages and cultures outside the US, including Hispanic languages and literature, French, romance languages and literatures, Italian, German, Slavic and more. In the social sciences, history had the highest percentage (25\%), followed by geography, political science, and anthropology. A perhaps more surprising finding was that, of the 398 languages that Berkeley has collected, 345 had no citations from any department during those eight years.

Giullian and Monroe-Gulick's 2017 assessment of the Slavic and Eurasian collection (and area studies more broadly) used a citation analysis of a random sample of the citations from 64 area studies faculty CVs. They found that foreign language material comprised $17 \%$ of the material cited across all regions (Slavic, East Asian, Latin American, and African), varying from 14 to 21\%, with the top subjects of languages, linguistics, literature, history, economics, and political science. The authors were not surprised by the high percentage of English language material used in area studies, stating that, "It's no secret that foreign language materials generally fall into the low-use category at academic libraries in North America," and identifying that the more important question is to focus on "how much" to spend on foreign language material.

The OhioLink study did not look at impact-just at usage-but it is valuable because of the size of the book collection that was analyzed. Almost $9 \%$ of the total collection-2,383,462 non-English language books-were held by the consortium's libraries. Their analysis found that the average circulation rate for books is 0.109 circulations per year. By contrast, the average circulation rate for the 14 most widely held languages was only 0.019. The most heavily used non-English books were in Spanish, but their rate-.065-was still well below the average. ${ }^{1}$

\section{Methods}

There are many measures we could use to evaluate the impact of our non-US collections on faculty research and teaching, potentially including qualitative measures (surveys, interviews, observations, focus groups) and quantitative measures (circulation statistics, online usage, course reserves, and citation analysis). Each measure has its own strengths and challenges. For example, circulation statistics may include books not actually read, yet citation counts may include materials which faculty accessed outside of library holdings, perhaps through personal collections, which might not be a good indicator of the library's collection strength. And while faculty increasingly rely on digital access, publishers specializing in foreign language materials or digitized primary sources may not provide online usage data.

After evaluating our options, we chose a mixed methods approach which allowed us to capture both faculty attitudes (how they feel about our collections and what they think they read) as well as behaviors (what they actually cite in their publications). This addresses the classic tension in both behavioral science and library science between what people do and what they say they do. ${ }^{2}$

We started by creating a database of all 509 faculty in the social sciences at Berkeley as determined by their faculty profiles and publications, with a particular note on their geographic focus. Our data services librarian, Joshua Quan, then created a visualization of faculty's geographic research interests by academic 
department. ${ }^{3}$ Following this, we identified four social science departments with significant research activity using non-English language materials: anthropology, history, political science, and sociology. Around three in four faculty in these four departments indicated a non-US research interest, whereas only one in four faculty in the other social science departments had comparable interests. And some departments, such as business and psychology, were wholly US-focused.

Within the four departments, we focused our survey and citation analysis on 107 faculty members who had significant global research interests. ${ }^{4}$ All full-time current faculty listed on department websites in 2017 were included, excluding only emeriti and temporary faculty hires.

We then searched for their publications over the last five years (2013-2017). When determining which publications to include in the citation analysis, we included only those with more than one reference, thereby excluding reviews of a single book. If a faculty member had published multiple versions of an article, we only included original versions published within 2013-2017, excluding reprints or translations of earlier work, as we wanted a bounded focus on their original citation choices in a given period of time.

To find these publications, we searched by date and faculty name in Scopus, Web of Science, CVs, disciplinary databases, and Google Scholar. ${ }^{5}$ We were able to extract about half of the needed citations using the Scopus API, and student workers manually entered other non-English language references into a spreadsheet. Librarians coded each non-English citation by language, and the assessment program librarian analyzed quantitative results in Excel and Tableau.

Following this analysis of faculty citations, we designed and distributed a survey in Qualtrics to 105 faculty in anthropology, history, political science, and sociology whose profiles listed research interests outside of the United States. ${ }^{6}$ This survey (see Appendix 1) asked how faculty acquire non-English material, the kinds of foreign sources they use, and their level of satisfaction with our support of global research. We also asked if they would participate in a follow-up structured interview or focus group to more deeply explore their needs for non-English material.

The response rate for this survey was a respectable $50 \%$, with responses strongest in history (72\%) and moderate in anthropology, sociology, and political science $(29,24$, and $24 \%$ respectively). Response rates were assisted by an email from the dean of the social sciences, and then by subject liaisons, encouraging participation. This assessment project would not have been possible without significant work on the part of student workers manually inputting the data, specialized language and technical data skills on the part of librarians, interlibrary loan staff who obtained the material not held at Berkeley, and librarian time dedicated to research.

\section{Citation Analysis Findings}

In order to analyze the frequency of foreign languages collection use in cited references, we started our publication search for the 107 faculty from the Scopus database and also from their CVs, disciplinary databases, Google Scholars, and others. Due to the lower coverage on social science content and book content, Scopus has only indexed $58 \%$ of the 107 faculty's publications, and $42 \%$ of the publications are identified somewhere else. One finding that surprised us was that the foreign language use patterns in cited references were extremely close between the Scopus and non-Scopus publications. The analysis below is based on all of the publications.

For the five-year time period (2013-2017), 737 publications from all 107 faculty were included in the citation analysis. By searching authors' names, 424 publications came from the Scopus database. The other 313 publications were identified manually. In total, 58,480 references were analyzed. On average, each faculty author published 7 items during the five-year period, and cited 79 references. The majority of faculty publications (57\%) were journal articles, while the majority of the cited references were books or book chapters (65\%). 
Of the 58,480 references, $16 \%(9,611)$ were in foreign languages with significant variations between history and the other three departments (see Figure 1). Thirty-six percent of the cited references from history were in foreign languages, but only $9-10 \%$ in anthropology, political science and sociology.

Figure 1. Frequency of non-English references cited by UCB faculty from 2013 to 2017 from the four departments: anthropology, history, political science, and sociology.

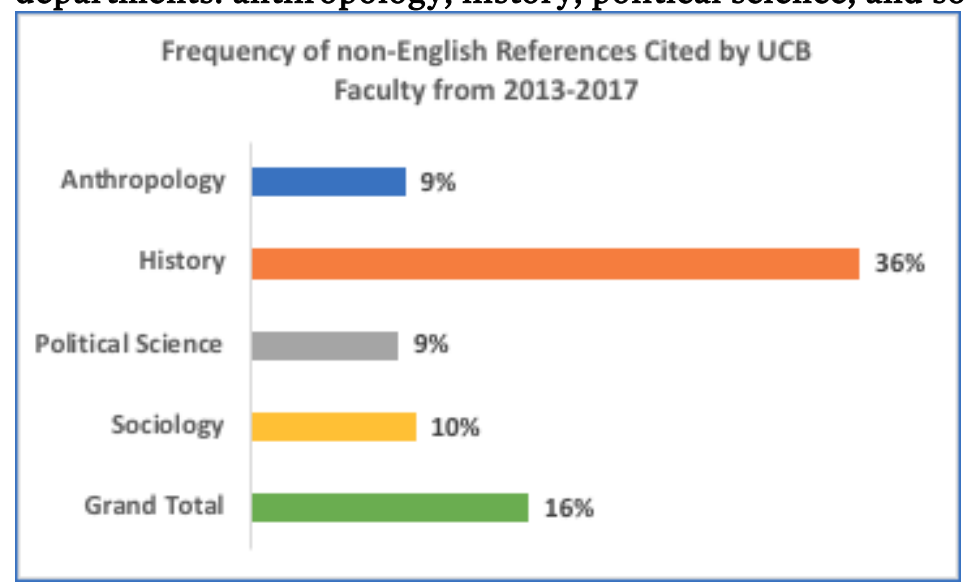

Among the 9,611 references in foreign languages, only 25 unique languages were identified (Figure 2), and the top 9 languages represented $98 \%$ of the references. The four departments have some variations, with Spanish being the most cited language for anthropology and political science, Italian for sociology, and French for history. The remaining 16 languages (Portuguese, Arabic, Greek, Turkish, Vietnamese, Swedish, Polish, Estonian, Danish, Norwegian, Hebrew, Dutch, Marathi, Kanuri, Hungarian, and Catalan) had low usage, and were cited less than two times annually by the faculty in the study.

Figure 2. Percentage of each foreign language cited across all the foreign language citations from 2013 to 2017 by UCB authors from the four departments: anthropology, history, political science, and sociology.

Non-English Languages Use Frequency in Cited References by UCB Faculty from Four Departments

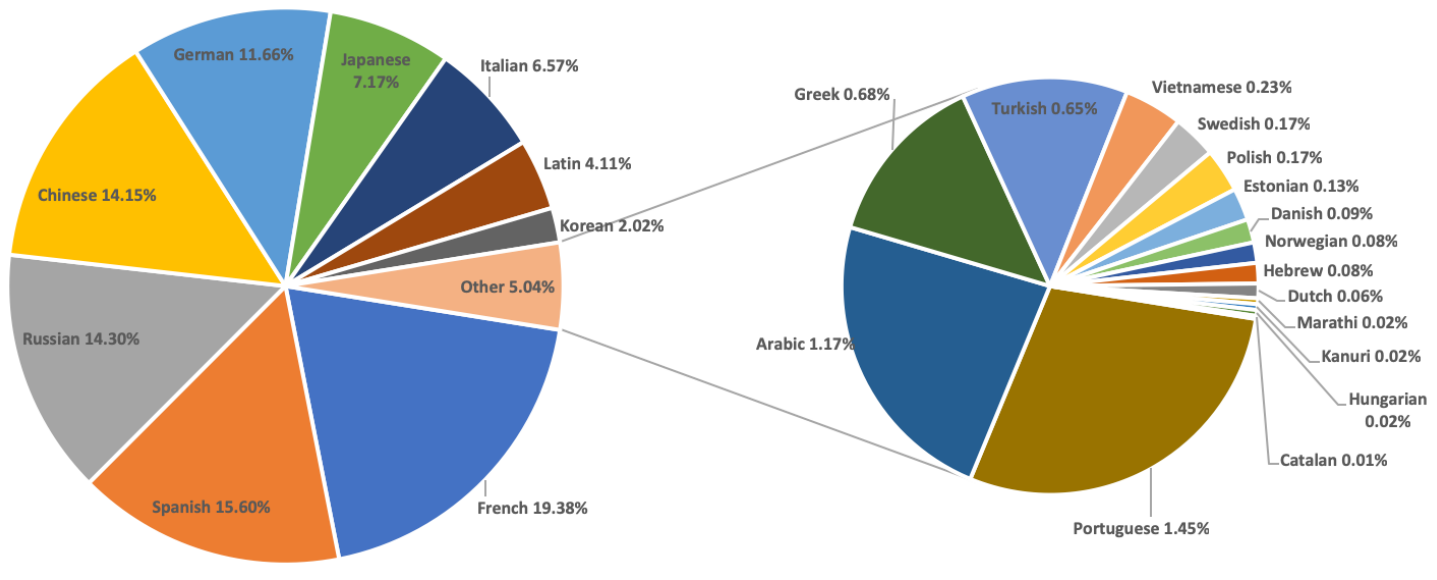

We also analyzed the citation trends of foreign language collections for the last five years. The percentage of cited foreign language collections varied a lot from year to year, ranging from 11 to $22 \%$. However, the 2017 citation rate of foreign language collections (16\%) is close to 5 years ago (19\%). Long-term monitoring is required in order to identify and analyze trends implications. 


\section{Survey Findings}

During spring 2018, a survey was sent out to 105 faculty members, to better understand the faculty's need for foreign language materials for their teaching and research and their satisfaction with the current library collections in this area. The overall response rate was $50 \%$. History was both the largest in terms of potential responders (39 faculty members) and had the highest response rate (72\%). Sociology, political science, and anthropology had fewer potential responders as well as a lower response rate, ranging from 24 to $29 \%$. Six faculty did not identify their department affiliations. Due to the higher representation from history, our overall survey findings can be driven by their responses. See Figure 3 for the responses distribution across departments.

Figure 3. Survey response percentages across the four departments: history, anthropology, political science, and sociology.

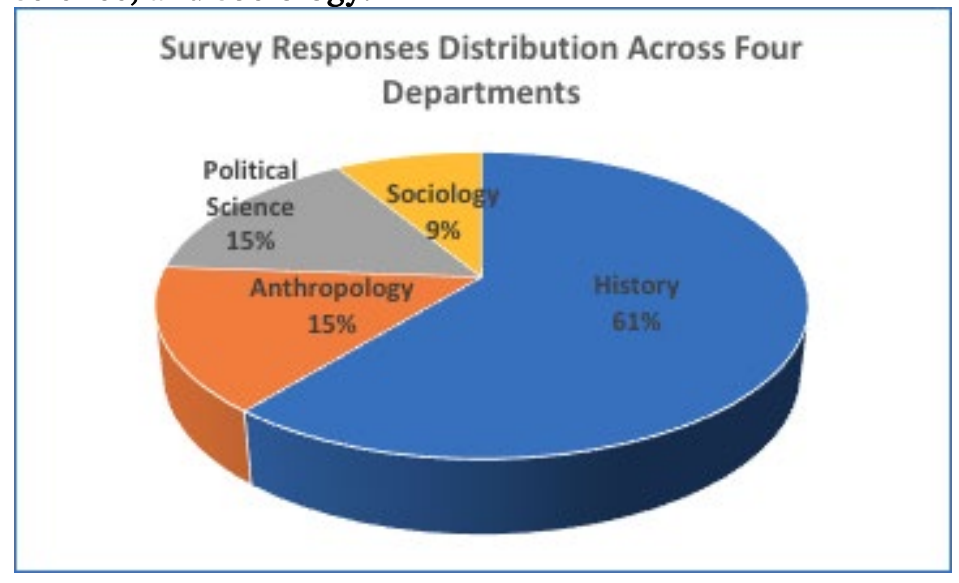

Faculty satisfaction with accessing international or foreign language material for research and teaching was high, with $80 \%$ stating that access to materials was satisfactory or great, and that the UC Berkeley Library (including interlibrary loan services) provided most of the material they needed, most of the time.

International travel, personal collections, and free resources were also identified as alternative channels for access. However, $14 \%$ requested improvements in access to foreign or international language materials for teaching, and $6 \%$ for their research. In comments, they noted gaps in the collection by area of the world, language, or format, as well as short loan periods for ILL. While overall we were pleased with the faculty's level of satisfaction with our collections, we did elicit some negative comments which we will explore more deeply in structured interviews, the next phase of this research project.

As to actual usage, faculty with research interests outside the US require heavy use of foreign language materials, with $80 \%$ saying they needed these materials over 20 times in the past five years. Many noted their frequent use of this material, commenting that our frequency scale was too low, with one estimating that two-thirds of all their research was conducted in foreign languages-"far more than 20+ times" in five years. Another added that "more than half the materials I use (and ALL of the primary sources) are in languages other than English." In terms of the types of material used, faculty noted academic books and journals most often, popular fiction and language learning material the least. History faculty again has the highest percentage (90-plus \%) of frequent users of materials in foreign languages and English-language material published outside of the US/UK. Even though the survey did not specifically ask about the needs for print versus electronic collections, there were a few comments about the desire for both formats.

The geographic focus of faculty research was widely distributed, with the largest single concentration in Western Europe (Figure 4): 
Figure 4. Percentage of each geographic area of focus identified via survey study across the four departments: anthropology, history, political science, and sociology

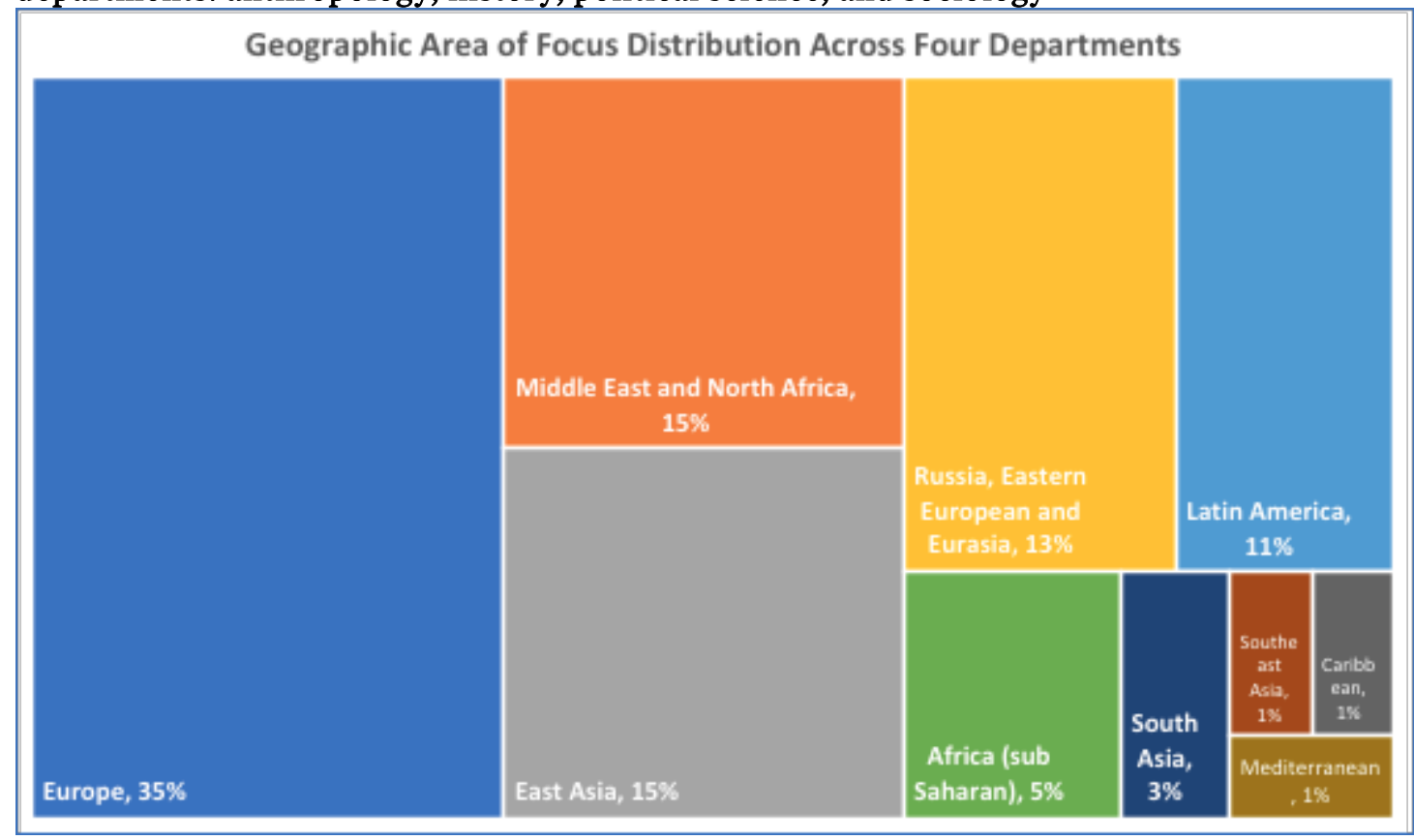

Languages used were diverse, with the most frequent being French, German, Spanish, Italian, Japanese, Portuguese, Russian, and Chinese (Figure 5). Another 21 languages were noted, several by only one person. Many respondents indicated that they frequently use more than one non-English language.

Figure 5. Percentage of each foreign language identified via survey study by UCB faculty from the four departments: anthropology, history, political science, and sociology.

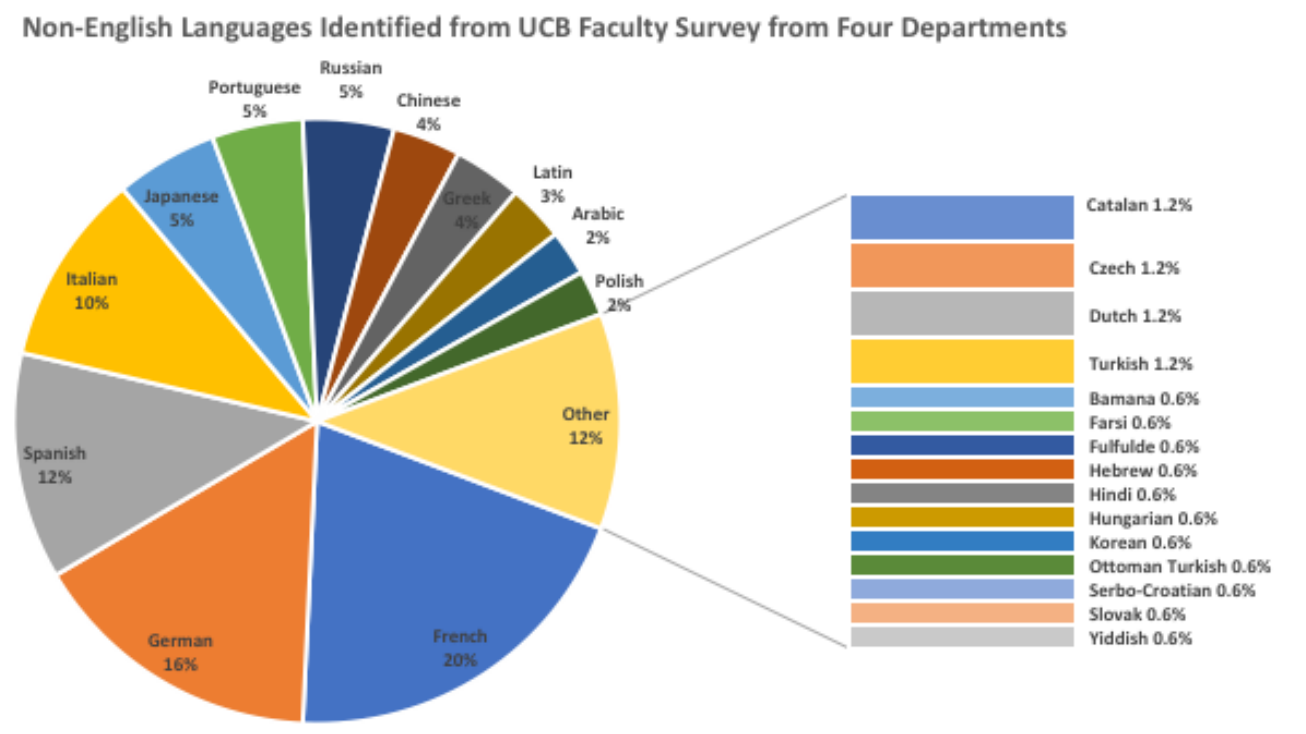

In the survey, many faculty commented on their heavy use of materials in not just one, but multiple foreign languages. Also, two faculty revealed a niche need for materials published in languages different from their area of focus, for example, Japanese material about China, or French/German material about Russian history. 
The core languages identified via survey study were very close to the languages cited by Berkeley faculty, including French, Spanish, Russian, Chinese, German, Japanese, Italian, Latin, Korean, Portuguese, and others. However, each study identified a few languages that the other study did not. The citation analysis and the survey identified a combined 36 languages in total (Figure 6).

Figure 6. Foreign languages identified from both citation analysis and survey study, including shared and unique ones.

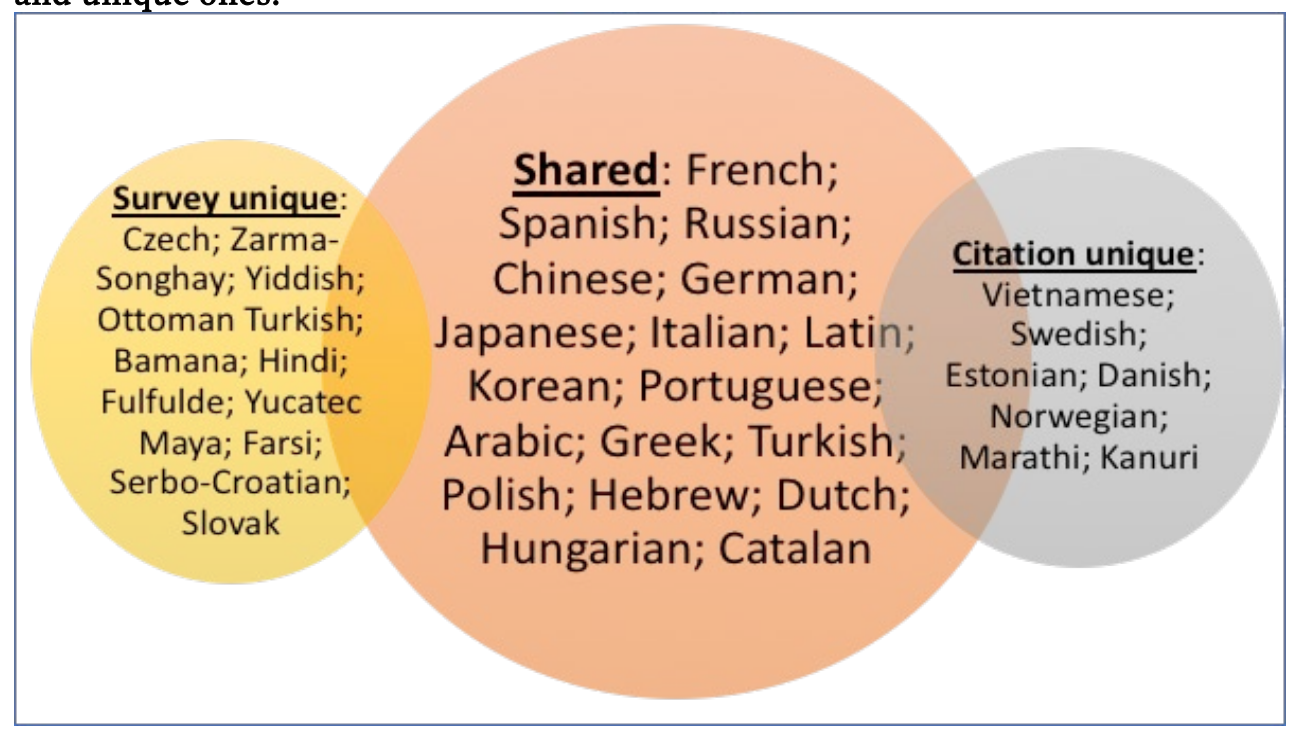

Faculty emphasized the importance of access to this material, noting that, "as a global research university, the library is essential to allowing us to meet [counter] the forces that push us toward monolingual, monocultural, insular, or provincial scholarship" and asserting that "high quality research remains largely dependent on library holdings on our campus.”

At the same time, a few faculty have expressed concerns about the impact of the library's recent budget cut on collections, and asserted the value of a "just-in-case" collecting strategy. One faculty commented:

Most of the books I currently use were acquired at a time when very few people at Berkeley read Russian, and they were purchased on the expectation of future use. Had volume of use been the criterion then, I would now have nothing to work with.

And another:

A good library collection lies at the heart of a major university. I would not have come to Berkeley as a full professor if the library system was mediocre and if the university were to downsize the library, it would be one of the reasons to consider leaving. The library needs to be protected at all costs.

\section{Conclusion: Practical Implications and Implementation}

This work has helped us get a much better sense of faculty needs and behaviors. The interactive visualization of the faculty's primary geographic focus enabled us to see, for the first time, the geographic interests of all 500-plus social sciences faculty. The database of faculty research interests by country enabled area studies librarians to identify the social sciences faculty with interests in their broad geographic areas. This is otherwise very difficult, if not impossible, since many areas (Latin America and Africa, for example) are not tied to an academic department and have highly interdisciplinary interests. 
Over time, the UC Berkeley Library has collected material in 398 languages. During the most recent fiscal year (2017/2018), the library cataloged items in 158 languages. Meanwhile, the citation analysis and the survey identified only 36 languages which the faculty felt were needed for their research and teaching. And of the total 398 languages ever collected, 373 were not cited even once by the four departments during the five-year period of the study.

When we began this project, we understood that non-English language material would be inherently lower use than English-but our findings indicate that the impact may also be lower than we thought, at least at the local level. We are aware that there are two important limitations to this study-we did not analyze the value that Berkeley adds to the broader academic community as a provider of content through interlibrary loan, and we did not analyze usage by departments outside the social sciences. We hope that both will be examined in the future.

But our findings have provided evidence that we need to make some changes in our collecting policies-and our funding allocations-in order to insure that collections are aligned with the institution's teaching and research needs in the social sciences.

-Copyright 2019 Susan Edwards, Chan Li, Celia Emmelhainz, Adam Clemons, Liladhar Pendse, and Natalia Estrada

Susan Edwards, Social Sciences Division Head, UC Berkeley

Chan Li, Assessment Program Librarian, UC Berkeley

Celia Emmelhainz, Anthropology and Quantitative Research Librarian, UC Berkeley

Adam Clemons, African and African American Studies Librarian, UC Berkeley

Liladhar Pendse, East European and Latin American Studies Librarian, UC Berkeley

Natalia Estrada, Reference and Collections Assistant, UC Berkeley

\section{Endnotes}

1. Gammon and O'Neill, "OhioLINK."

2. Heath, "Applying Human-Centred Design," 51.

3. "Social Sciences Faculty Research Geographies," RPubs, http://rpubs.com/jq834488/296789.

4. This means that both our citation analysis and survey are focused on faculty with global research interests, and are most relevant to other areas with a strong global focus.

5. For more on this strategy, see: Emmelhainz and Estrada, Searching for Recent Anthropology."

6. 107 surveys were originally sent out, but one professor passed away and another left the university.

\section{References}

Edwards, Susan, Lynn Jones, and Scott Paul McGinnis. "Big Data for Big Questions: Assessing the Impact of Non-English Language Sources on Doctoral Research at Berkeley.” In ACRL Proceedings, 13. Baltimore, MD: American Library Association, 2017.

http://www.ala.org/acrl/sites/ala.org.acrl/files/content/conferences/confsandpreconfs/2017/BigDatafo rBigQuestions.pdf.

Emmelhainz, Celia, and Natalia Estrada. "Searching for Recent Anthropology and Archaeology Publications.” ANSS Currents 33, no. 1 (2018): 17-21. https://escholarship.org/uc/item/94c8t9sk.

Gammon, Julia, and Edward O'Neill. “OhioLINK-OCLC Collection and Circulation Analysis Project.” Dublin, Ohio: OCLC, 2011. https://www.oclc.org/content/research/publications/library/2011/201106r.html.

Giullian, Jon C., and Amalia Monroe-Gulick. "Assessment of KU Libraries' Slavic \& Eurasian Collection: Purpose, Process, and Potential.” Slavic \& East European Information Resources 18, no. 1-2 (2017): 49-66. https://doi.org/10.1080/15228886.2017.1322382. 
Heath, Paul-Jervis. “Applying Human-Centred Design to the Library Experience.” In User Experience in Libraries: Applying Ethnography and Human-Centred Design, 49-67. Edited by Andy Priestner and Matt Borg. New York: Routledge, 2016.

Kellsey, Charlene, and Jennifer E. Knievel. "Global English in the Humanities? A Longitudinal Citation Study of Foreign-Language Use by Humanities Scholars.” College \& Research Libraries 65, no. 3 (2004): 194-204.https://doi.org/10.5860/crl.65.3.194.

Knievel, Jennifer E., and Charlene Kellsey. "Citation Analysis for Collection Development: A Comparative Study of Eight Humanities Fields 1.” The Library Quarterly 75, no. 2 (2005): 142-168.

Schadl, Suzanne M., and Marina Todeschini. "Cite Globally, Analyze Locally: Citation Analysis from a Local Latin American Studies Perspective.” College \& Research Libraries 76, no. 2 (2015): 136-49. https://doi.org/10.5860/crl.76.2.136. 
Appendix 1: Text of Survey Instrument in Qualtrics

Foreign Language and International Publications

Welcome! As we make difficult decisions about future collection development, we need your input. This survey is focused on your experience obtaining the print and e-resources that you need to support your research on countries outside of the US/UK, and in languages other than English.

Q1. Do you, or do graduate students you work with, currently conduct research that relies on primary or secondary materials published outside of the US/UK and/or in languages other than English?

Yes-keep going

No-end of survey

Q2. In the past five years, how often have you used the following print or electronic resources for your research:

Materials published in a non-English language?

[Choices: 0, 1-10, 11-20, more than 20 times]

Materials published outside of the US/UK [in English]?

[Choices: 0, 1-10, 11-20, more than 20 times]

Q2b. [Comments:]

Q3. In the past five years, how often have you used the following types of print or electronic resources in foreign languages?

[Choices: 0, 1-10, 11-20, more than 20 times]

Academic books

Academic journals

Data (non-governmental)

Government information (including data)

Language-learning materials (primers, low-level children's books)

Multimedia (film, images, sound recordings)

Newspapers

Popular fiction

Reference works (dictionaries, bibliographies, encyclopedias)

Special Collections (rare or archival material) 
In the past five years, how often have you used the following types of print or electronic resources published outside of the US/UK?

Academic books

Academic journals

Data (non-governmental)

Government information (including data)

Language-learning materials (primers, low-level children's books)

Multimedia (film, images, sound recordings)

Newspapers

Popular fiction

Reference works (dictionaries, bibliographies, encyclopedias)

Special Collections (rare or archival material)

Q3b. [Comments]

Q4. Besides English, what other languages do you utilize in your Library research?

\section{[multi-select]}

Chinese

French

German

Japanese

Portuguese

Russian

Spanish

Other:

Q5. Outside of the US/UK, what is your geographic area of focus?

[multi-select]

Africa (sub-Saharan)

East Asia

Europe 
Latin America

Middle East and North Africa

Russia, Eastern European and Eurasia

South Asia

Southeast Asia

Other:

Q6. In the past five years, how have you obtained material published outside of the US/UK that you need for your research??

[Choices: Most of the time, Some of the time, Rarely, Never]

UC Berkeley Library (including NRLF)

UC Berkeley's Interlibrary Loan Service

International travel

Buy for my own (or my research team's) personal collection

Request via personal networks

Freely available online

Q6b. [Comments:]

Q7. Please rate your satisfaction in accessing international or foreign language resources for your research:

[Choices: Great, Satisfactory, Needs Improvement, Not Applicable]

Q7b. Please provide positive or negative feedback to help us improve:

Q8. The next question switches focus from your research to your teaching:

Please rate your satisfaction in accessing international or foreign language resources for your teaching at UC Berkeley:

[Choices: Great, Satisfactory, Needs Improvement, Not Applicable]

Q8b. [Comment] Please provide positive or negative feedback to help us improve:

Q9. What is your primary departmental affiliation?

Anthropology

History

Political Science 
Sociology

Q10. Are you affiliated with one or more area studies centers or institutes on campus?

[multi-select]

Center for African Studies

Center for Latin American Studies

Center for Middle Eastern Studies

Center for Southeast Asia Studies

Institute of East Asian Studies

Institute of European Studies

Institute of Slavic, East European and Eurasian Studies

Q11. Any other comments:

Open text:

Q12. Are you interested in contributing to an interview or focus group so that we can learn more about your Library needs?

If so, please let us know how to contact you.

Name

Email

Thank you!

Appendix 2: Academic departments included in the social sciences at Berkeley

African American Studies

Anthropology

Business

Demography

Economics

Education

Environmental Design (Architecture)

Environmental Design (City and Regional Planning)

Environmental Design (Landscape Architecture) 
Ethnic Studies

Gender and Women's Studies

Geography

History

Information

Linguistics

Political Science

Psychology

Public Policy

Social Welfare

Sociology 